\title{
Shaker rig test of EB25 GRP boogie
}

\author{
R. Chvojan ${ }^{1 \mathrm{a}}$, R.Jozefy ${ }^{1}$, R.Mayer ${ }^{2}$, and J. Václavík ${ }^{1}$ \\ ${ }^{1}$ SKODA VYZKUM s.r.o., Dynamic Testing Laboratory, Tylova 1/57, 31600 Plzeň, Czech \\ Republic \\ ${ }^{2}$ Sciotech Projects and University of Reading, University of Reading, Whiteknights, Reading, \\ RG6 6AY, United Kingdom
}

\begin{abstract}
The aim of this article is to describe the design of GRP bogie frame and the performance of testing procedures for this frame, made in Dynamic testing laboratory in SKODA VYZKUM s.r.o. Tests of bogie longitudinal beam set-up are introduced, including static, sweep, harmonic oscillation and drop tests. Initial tests at shaker test rig of GRP25-1 bogie on Smms wagon are also described. The test evaluation includes the damping coefficients, natural frequency and beam strains and deflection during the tetsts of the structure.
\end{abstract}

\section{Introduction}

A cost effective bogie is developed at revolutionary design by the use of advanced fibre reinforced plastics composites operating under extreme load bearing conditions in a hostile environment. The thick section composite bogie is created from a suitably aligned preform using resin transfer moulding to produce a cost effective product. The object of the project is to design, demonstrate and achieve Technical Specfication for Interoperability (TSI) approval of a novel lightweight bogie as an interoperability constituent, to obtain TSI certifcation of a container wagon fitted to this bogie and to demonstrate that the bogie/wagon will generate significantly less noise and track damage than any conventional steel bogie.

The topic of load bearing components made from fibre-reinforced plastics has been under investigation since 1992 to develop advanced suspensions for road and rail vehicles within two Eureka projects namely E! 888 Eurospring and E! 1841 Eurobogie. These components have been tested in the laboratory [1], on test tracks and in-service.

Advantages include: lightweight bogie so wagon can carry higher payload, ride height remains constant in service, reproducible and reliable damping utilising intrinsic properties of GRP and rubber, minimal frictional damping due to internal damping of rubber and GRP, low dynamic load coefficient for well aligned track, intrinsic attenuation of noise and vibration so eliminating body vibrations and noise, low maintenance and long life components and easy assembly from "kit" of component parts.

The aim of this article is to decribe the design and performance of comprehensive testing procedures for GRP bogie frame, made in Dynamic testing laboratory in SKODA VYZKUM s.r.o.

\footnotetext{
a e-mail : jan.chvojan@ @kodavyzkum.cz
} 


\section{GRP bogie}

\subsection{Bogie description}

This 22.5 tonnes per axle bogie comprises an upper and lower bogie GRP frame (Figure 1a). These frames are moulded direct to the final shape and under load the bogie frames deflect to provide the suspension part of the bogie (Figure 1b).

The properties of advanced glass fibre reinforced plastic (GRP) composites allow the functions of the frame, suspension and damper elements to be integrated, thereby reducing the number of discrete components and joints. Unlike steel, the use of such materials allows the bogie frame to be tuned to provide the optimum stiffness properties in the principal orthogonal directions. The use of resilient elements in the axle box and at discrete parts of the bogie frame provides inherently high damping compared to steel, with the additional benefit of substantially reducing generation and transmission of noise.

The latter results in the substantially improved ride quality and reduction in the track force, particularly under laden conditions when most track damage can occur. Conventional steel bogies are generally too stiff in the lateral, torsional and lozenging directions, which results in an excessive track force when going round corners or along a poor track quality. The composite bogie is designed to be more compliant in these directions, which allows the wheel to follow more accurately the line of the track, with consequently a corresponding reduction in track forces and improved ride quality.
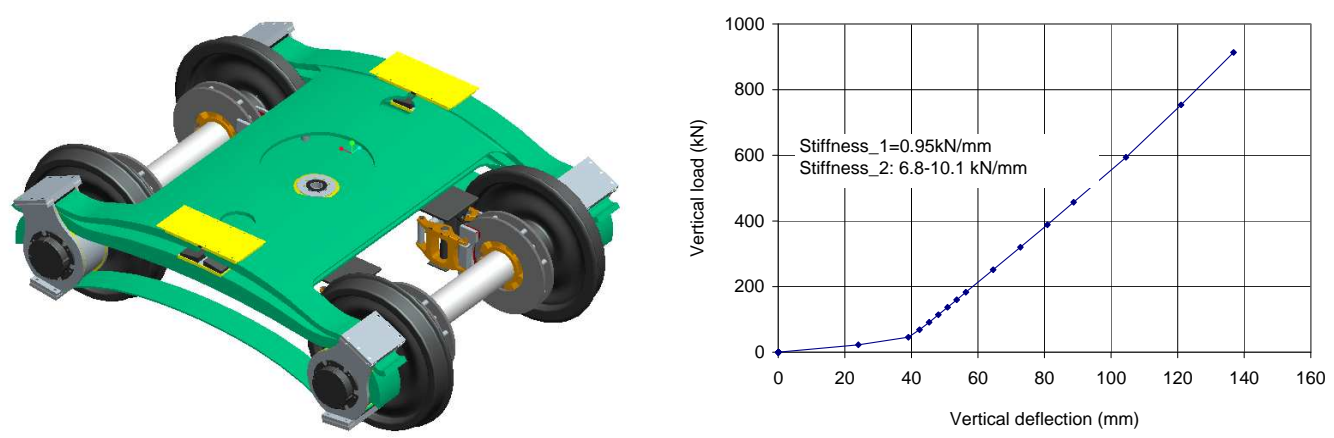

Fig. 1. GRP25-1 bogie a) and its double stiffness vertical deflection curve b)

\subsection{Fifth-scale GRP bogie}

The concept of GRP bogie was evaluated at fifth-scale by making, instrumenting and testing two bogies which have been in service for 4 years fitted to a passenger wagon at Southampton's Lakeside Railway to study the interactions betwen the truck and the wagon. Every feature of the full scale bogie has been replicated including the axle box, central pivot point and the disc brakes. Two different suspension types were monitored during the runs at the Eastleigh railway track: a steelbogied wagon and a GRP-bogied wagon.

The effect of the distributed damping elements within the GRP-bogie is to substantially reduce the amplitude and frequency of the track inputs - in the horizontal by a factor of up to 50, and in the vertical direction by a factor of up to 5. It seems on the basis of this dynamic evidence that the GRP bogie has much better damping characteristics in the horizontal than in the vertical direction.

Sprung mass frequencies are almost always higher in the steel wagon than in the GRP bogied wagon. The biggest differences are found in the case of the vertical accelerations. Typically 5 times higher for the vertical and 1.6 times higher for the horizontal acceleration. This cannot simply be explained by the differences in static mass and stiffnesses as the GRP bogie is statically stiffer but appears to be dynamically softer. In the empty condition the GRP bogied wagon seems to have higher vertical frequencies compared to the fully laden case. This implies that the GRP bogie is 
acting as a low-pass filter; that is, only low frequencies can be excited and all higher frequencies are filtered out. The vertical frequency of the steel bogied wagon is almost as high as that of the GRP bogie which only comprises the unsprung mass.

The peak accelerations of the sprung mass are as much as 4 times higher in the horizontal than in the vertical direction. These accelerations increase by a factor of 1.5 between unladen and laden conditions.

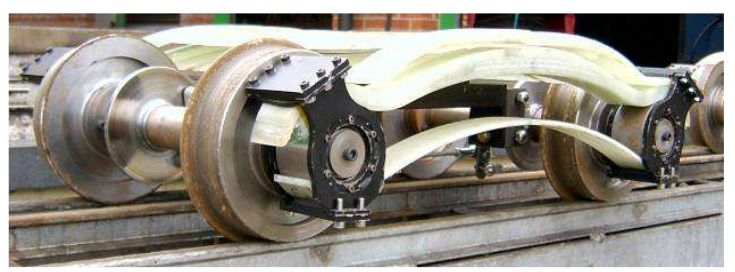

Fig. 2. Fifth scale GRP bogie

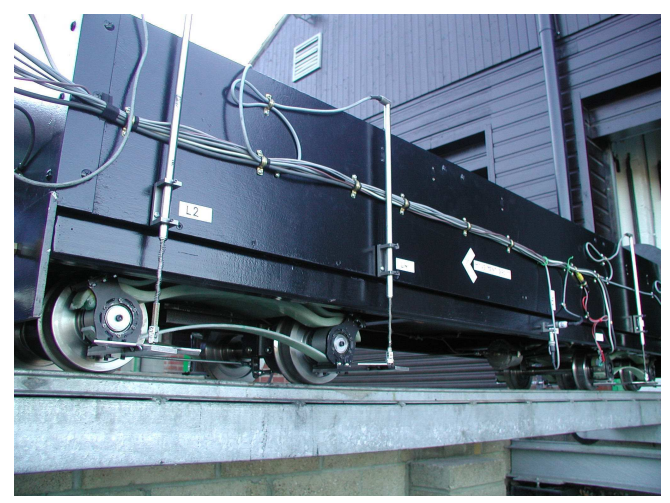

Fig. 3. Wagon with fifth scale bogie

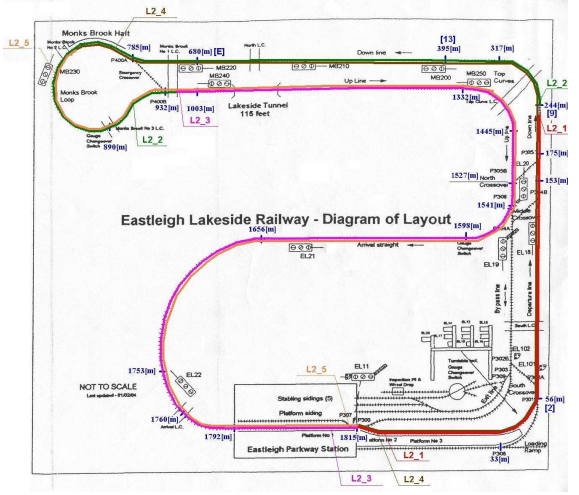

Fig. 4. Tested railway loop

Table 1. Properties of tested fifth scale bogie

\begin{tabular}{|l|c|c|}
\hline Property & Steel bogied wagon & GRP bogied wagon \\
\hline Lateral stiffness [N/mm] & 2100 & 3600 \\
\hline Vertical stiffness [N/mm] & 830 & 1250 \\
\hline Gravity force - unladen [N] & 2200 & 980 \\
\hline Gravity force - laden [N] & same & 6300 \\
\hline
\end{tabular}

Table 2. Obtained natural frequencies of fifth scale bogie and bogied wagons

\begin{tabular}{|l|c|c|c|}
\hline Direction / wagon state & $\begin{array}{c}\text { GRP } \\
\text { bogie }\end{array}$ & $\begin{array}{c}\text { Steel bogied } \\
\text { wagon }\end{array}$ & $\begin{array}{c}\text { GRP bogied } \\
\text { wagon }\end{array}$ \\
\hline Vertical - unladen $[\mathrm{Hz}]$ & 110 & 25 & 70 \\
\hline Vertical - laden $[\mathrm{Hz}]$ & 120 & 15 & - \\
\hline Horizontal - unladen $[\mathrm{Hz}]$ & 110 & 15 & 30 \\
\hline Horizontal - Iaden $[\mathrm{Hz}]$ & 120 & 20 & - \\
\hline
\end{tabular}

Table 3. Measured peak accelerations at bogied wagons

\begin{tabular}{|l|c|c|}
\hline Wagon state & Vertical & Horizontal \\
\hline Unsprung mass - unladen $\left[\mathrm{m} \cdot \mathrm{s}^{-2}\right]$ & 8 & 33 \\
\hline Unsprung mass - laden $\left[\mathrm{m} \cdot \mathrm{s}^{-2}\right]$ & 12 & 48 \\
\hline Sprung mass - unladen $\left[\mathrm{m} \cdot \mathrm{s}^{-2}\right]$ & 2.8 & 2.6 \\
\hline Sprung mass - laden $\left[\mathrm{m} \cdot \mathrm{s}^{-2}\right]$ & 2.7 & 2.3 \\
\hline
\end{tabular}




\section{Tests on full scale one-half bogie}

The main investigations were performed with the full scale set bogie composite beams (bottom axle tie, compact lower beam and split upper beam, connected with axle boxes), just forming one side of composite bogie (see Figure 5). The vertical loading was performed through a steel plate with the help of one hydraulic cylinder $250 \mathrm{kN}$ with the stroke of $250 \mathrm{~mm}$, controlled via system Labtronic, both produced by IST. The lower beam was provided with three pairs of strain gauges positioned at edges from the bottom side (two near axle boxes $-\mathrm{T}_{1}, \mathrm{~T}_{2}$ and $\mathrm{T}_{5}, \mathrm{~T}_{6}$ ), one in the middle $-\mathrm{T}_{3}, \mathrm{~T}_{4}$ ). Two strain gauge rosettes $R_{1}, R_{2}$ were put to the lower beam side wall, one near the axle box, the other at the beam centre for checking the sheer strain. The beam deflection was measured with a laser displacement sensor. The acting force and displacement of the hydraulic cylinder were measured as well.

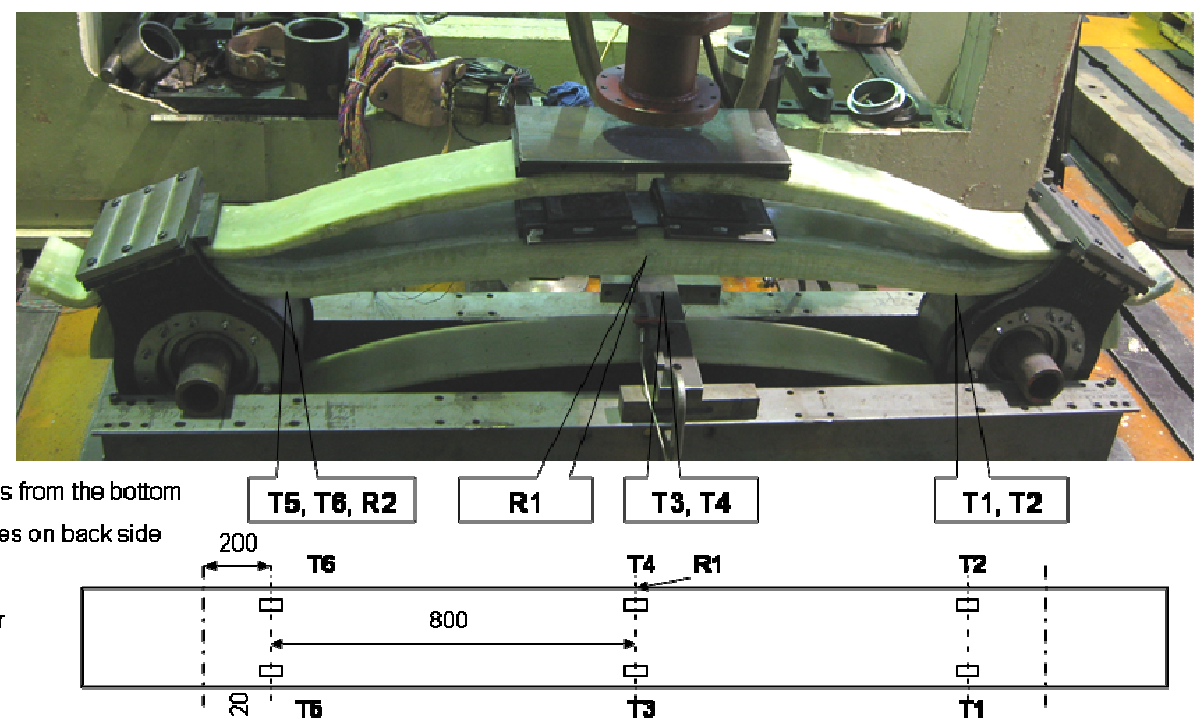

Fig. 5. Set-up of the tested one-half GRP bogie, full scale

\subsection{Static loading}

The aim of this test was to obtain the relationship between force, deflection and GRP beam strain under static vertical compressive load up to $250 \mathrm{kN}$, as this value represents $25 \%$ above laden load.
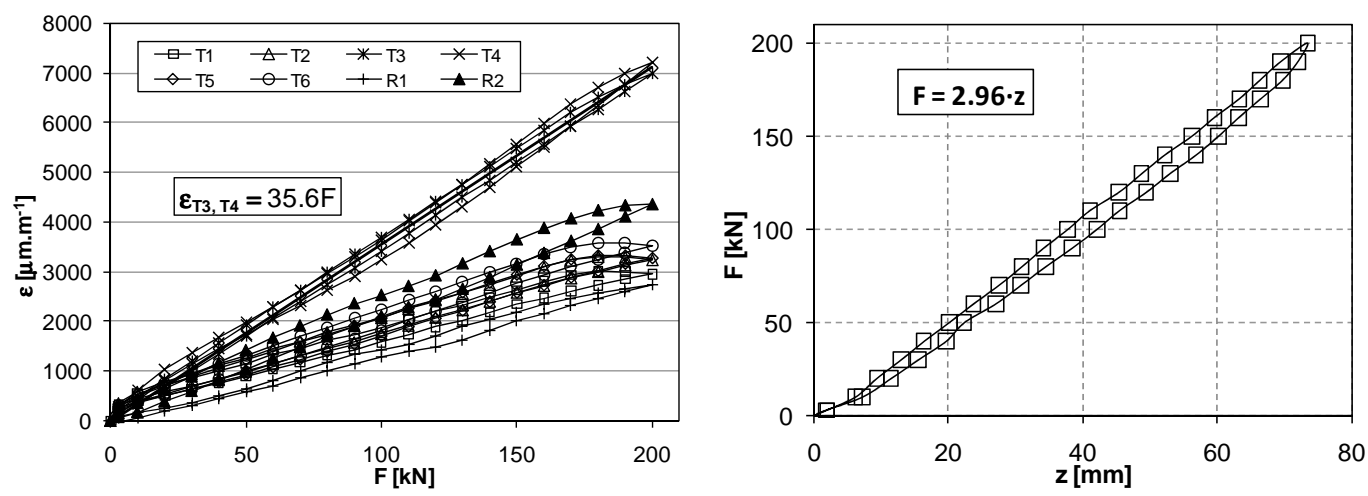

Fig. 6. Static characteristics of GRP one-half bogie 
The static characteristics of the sample during loading and unloading are given in Figure 6. The main findings of the performed test were : the beam fits the conditions of the maximum force without breaking, the rest deflection after unloading was $5.2 \mathrm{~mm}$, the mutually extension of axle boxes was $0.3 \mathrm{~mm} \cdot \mathrm{kN}^{-1}$ and the stifness of the beam set-up was $2.96 \mathrm{kN} \mathrm{mm}{ }^{-1}$. The sheer strains, evaluated from strain gauge rosette, is higher near axle boxes than in the beam middle nearly twice but still lower, in comparison with bending strains.

\subsection{Drop test}

The aim of this test is to find the natural frequency and Coulomb damping of the free excited beam set-up. The beam was lifted with one side up and then dropped from the high of $50 \mathrm{~mm}$.

The evaluation of the the mean logarithmic damping decrement $\delta$, critical damping ratio $\zeta$ and natural frequency $\omega_{0}$ was performed from discrete positive or negative peaks - decay of $n$-orders of amplitudes $q_{i}$ (see Figure 7a) according relations (1); $\omega_{d}=2 \pi / \mathrm{T}_{\mathrm{d}}$ is a circular frequency of the oscillation of the dampened system

$$
\bar{\delta}=\frac{1}{n} \cdot \ln \frac{q_{i}}{q_{i+n}}, \quad \bar{\zeta}=\frac{\bar{\delta}}{2 \pi}, \quad f_{o}=\frac{\sqrt{1+\bar{\zeta}^{2}}}{\bar{T}_{d}}
$$

An obtained response at the strain gauge $\mathrm{T} 1$ and the beam deflection $z$ is drawn in Figure $7 \mathrm{~b}$. Following results were obtained from the drop test. The logaritmic decrement $\delta \in\langle 0.2 ; 0.3\rangle$, critical damping ratio $\zeta \in<0.03 ; 0.05>$ and natural frequency $f_{0} \in<13 ; 14>\mathrm{Hz}$.
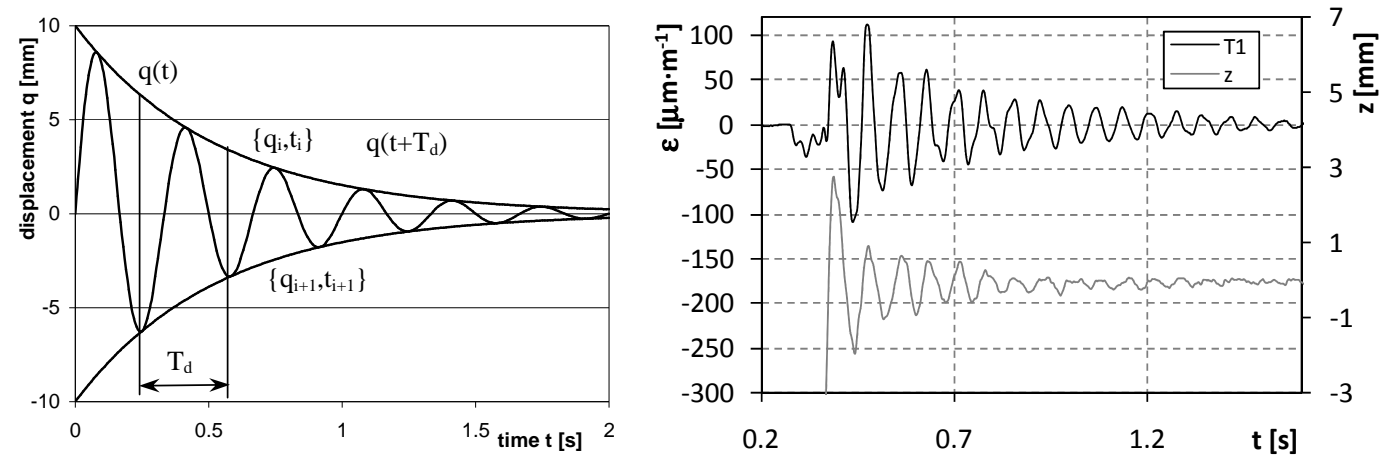

Fig. 7. Theoretical response to the drop test and measured responses of the strain and beam deflection

\subsection{Beam set-up sinusoidal excitation}

The damping capacity was determined from an energy dissipation under cycling conditions. The main sources of the damping in a composite material arise from the viscoelastic phenomena associated with the matrix and from the relative sliping at the interface between the matrix and the reinforcement.

The testing characteristics of the practical case of the cycle load acting on a material sample are represented graphically in Figure 8. The beam was subjected to the oscillating load amplitude $F_{a}$, which was superimposed on the static preload $F_{m}$. This procedure enables the establishment of a load deflection curve as the the hysteresis loop, which area is equal to the energy dissipated per loading cycle $\Delta W$ (Figure 8 ). This energy was calculated by integrating the full displacement - force curve. The specific damping capacity (loss factor) $\Psi$ describes the ratio of the dissipated energy to the total absorbed energy per cycle $W$, from which a critical damping ratio $\zeta$ also can be calculated according to the relation (2). 


$$
\Psi=\frac{\Delta W}{W}=1-\frac{1}{e^{4 \pi \zeta}} \quad \zeta=\frac{1}{4 \pi} \ln \left(\frac{1}{1-\Psi}\right)
$$
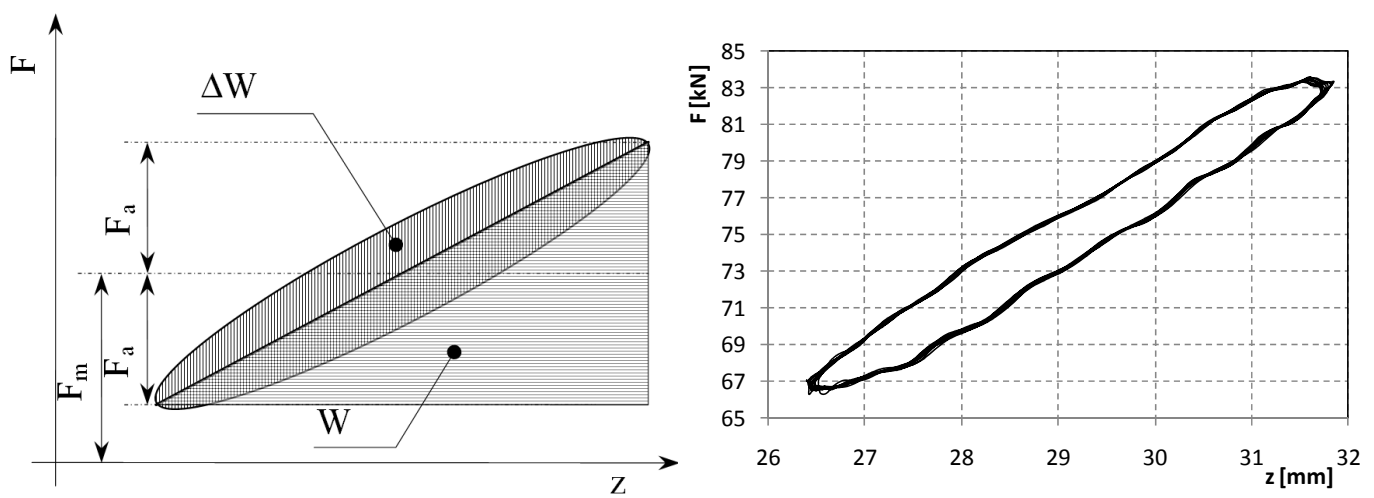

Fig. 8. Theoretical hysteresis loop under the cyclic loading and the measured loop for $F_{s}=75 \mathrm{kN}, F_{a}=10 \mathrm{kN}$,

$$
f=5 \mathrm{~Hz}
$$

The same test was performed for three static preloads $\mathrm{F}_{\mathrm{m}} \in\{35 ; 75 ; 115\} \mathrm{kN}$, force amplitude $\mathrm{F}_{\mathrm{a}}=10 \mathrm{kN}$ and for frequencies $\mathrm{f} \in\langle 1 ; 10\rangle \mathrm{Hz}$ at step $\Delta f=1 \mathrm{~Hz}$.

From each test the critical damping ratio $\zeta$ from (2) was calculated and is drawn in Figure 9.

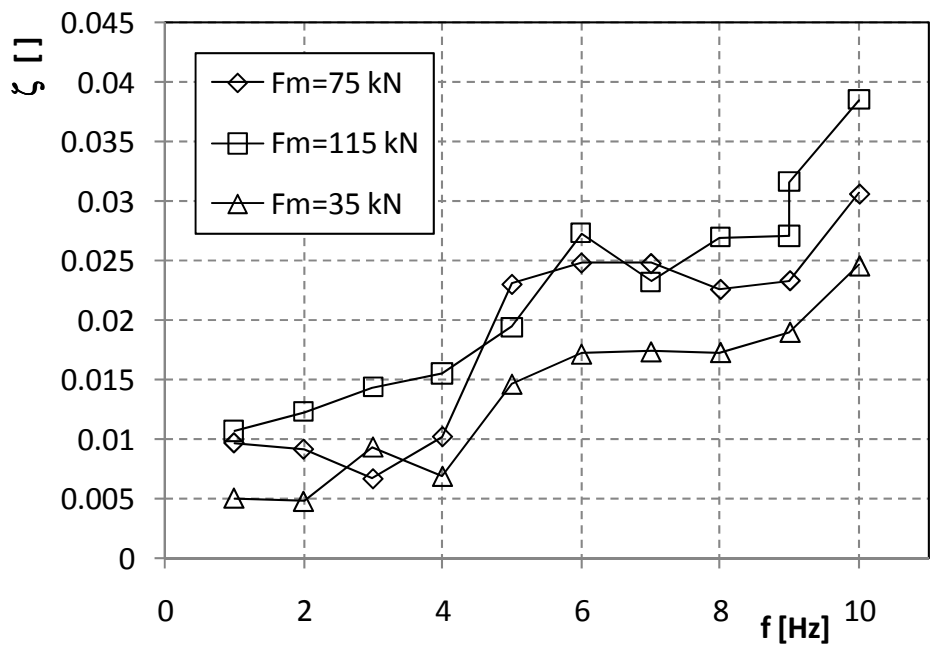

Fig. 9. Relation of evaluated critical damping ratio $\zeta$ vs. excited frequency $f$ and mean prestress $F_{m}$

\subsection{Sweep test}

The natural frequency of the beam set-up were investigated during the sweep test with the constant displacement of the hydraulic cylinder of $1 \mathrm{~mm}$. The frequency was varied in the interval of $\langle 0 ; 30\rangle$ $\mathrm{Hz}$ with the rate $0.2 \mathrm{~Hz} \cdot \mathrm{s}^{-1}$. The test was performed four times with the four static preloading levels: $\mathrm{F} \in\{30 ; 50 ; 70 ; 90\} \mathrm{kN}$. The time history for three measured variables during the sweep test is given in Figure 10. The spectral density function ASD for the acting force and beam displacement for all force preloads is given in Figure 11.

Two main resonance frequencies were visible on the evaluated charts in frequency domain. The first low inexpressive probably bending frequency and the second higher very sharp hoop 
frequency.The bending frequency lies in interval $\langle 11 ; 15\rangle \mathrm{Hz}$ obtained from all measured signals instead of the force, where it was observed in interval $\langle 8 ; 9\rangle \mathrm{Hz}$. The hoop frequency was red out to be $19.5 \mathrm{~Hz}$.
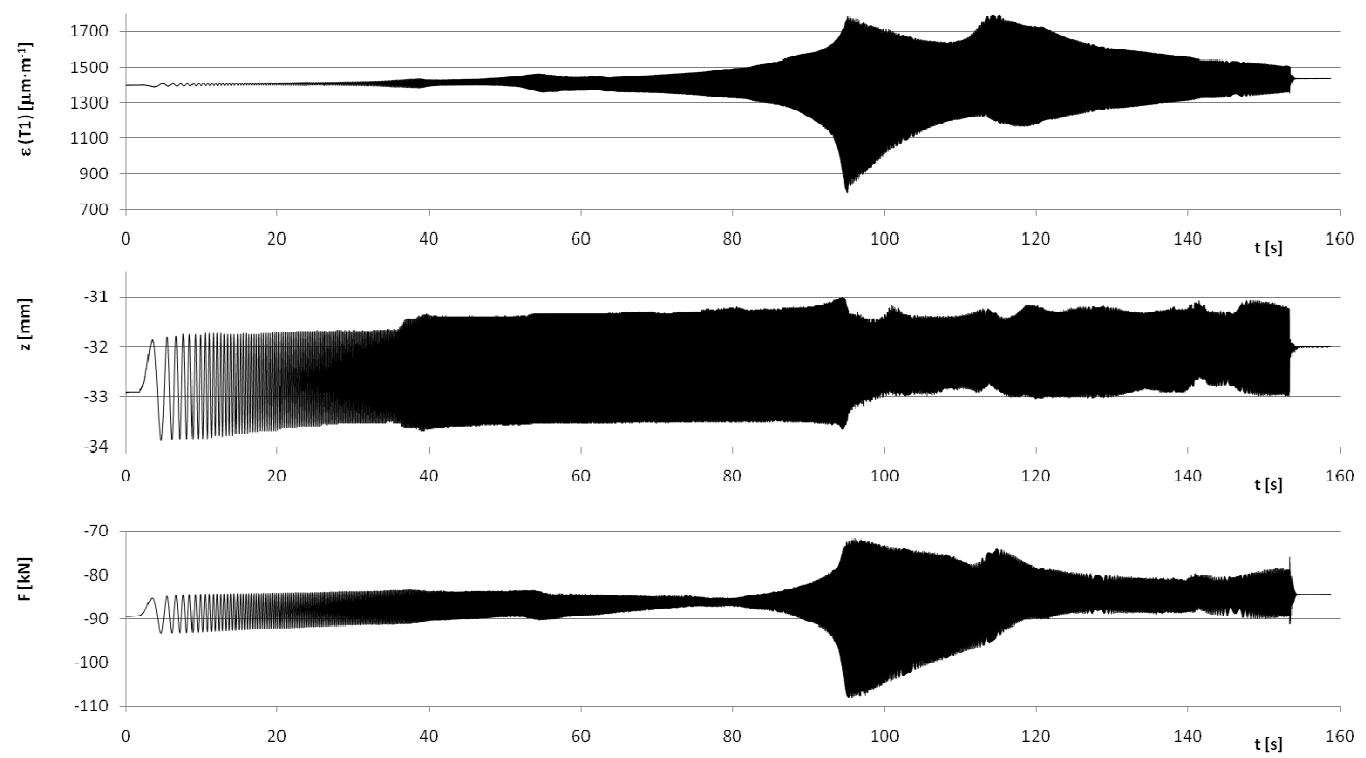

Fig. 10. Sweep test response at $F_{m}=90 \mathrm{kN}$ for strain $\varepsilon$ at gauge T1, beam deflection $z$ and loading force $F$
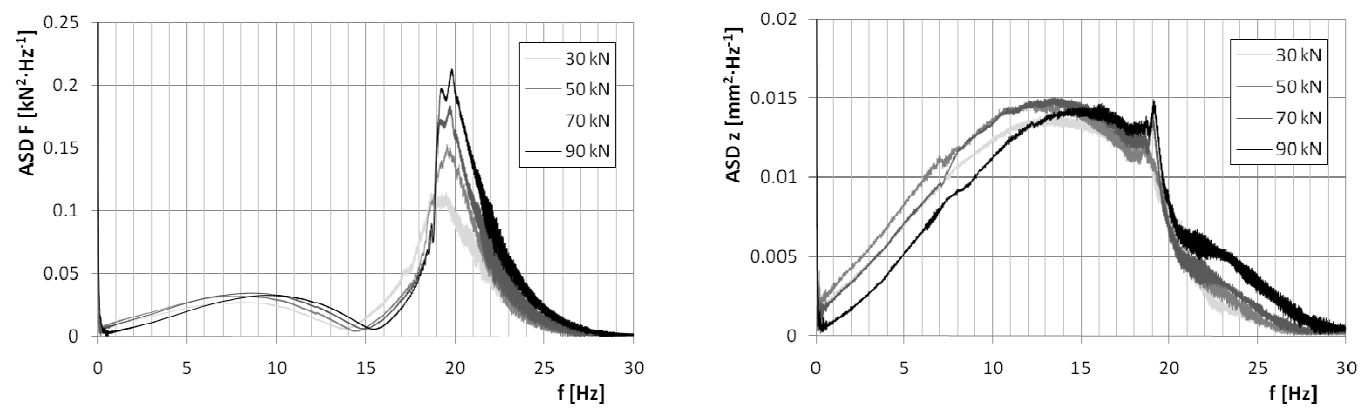

Fig. 11. Sweep test response (a) and ASD of acting force $F$ and beam deflection $z$

\section{Shaker rig test}

SKODA VYZKUM s.r.o. has developed the shaker test rig for testing of the whole rail vehicle at various performance conditions as well as with various suspension types to get these interactions using electro-hydraulic testing system Schenck.

As GRP bogie concerns, only one bogie was assembled on the wagon and loaded. The second bogie was dissembled. The wagon was supported under the second bogie with the rigid cube. Here, the performance characteristics and interactions have been tested on Smms wagon with GRP25-1 bogie (Figure. 12).

In the frame of the whole bogie development the static tests were performed with the bogie by that time. The deflection of the composite bogie and the change of wheel base was studied when the wagon was loading with concrete panels on the test rig (Figure 13). The wagon was tested at six load states (tare and load with five concrete panels with $1400 \mathrm{~kg}$ mass of each). The panels were put on to the Smms wagon right over the bogie centre. 

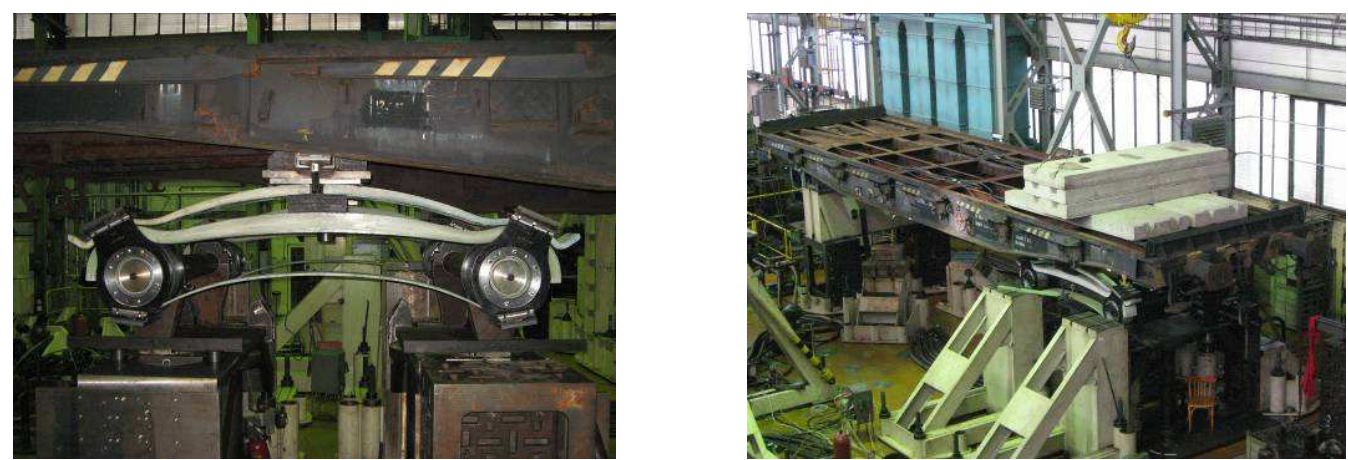

Fig. 12. The GRP bogie and Smms wagon at the shaker rig during the stiffness test (loading with panels)
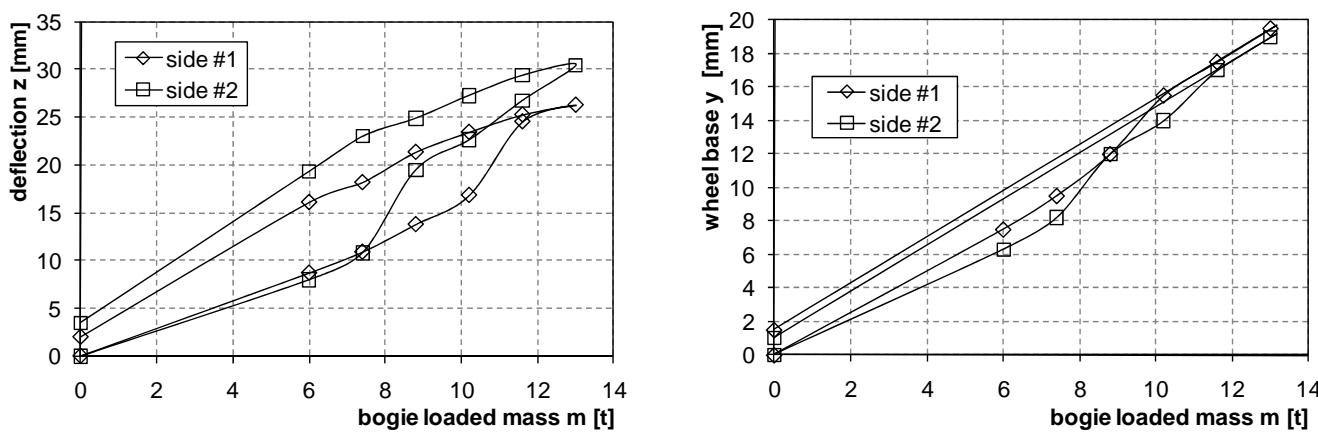

Fig. 13. Bogie deflection and change of wheel base during static loading test of the GRP bogie

\section{Conclusion}

The shaker rig method is valid for bogie vehicles as well as axle wagons. Next work is performance of drop, sweep and track test of the full scale GRP bogie on the shaker rig. Standardized tests of the bogie according UIC methodology are planed as the final work.

The authors thank the Eureka Unit, Czech Republic for the financial support of this project, which is led under internal notification OE 196 and the Department of Trade and Industry, UK.

\section{References}

1. J.Chvojan, J.-Y. Cherruault, M.Kotas, M. Rayner and J.Václavík, Dynamic investigations on freight wagon suspensions", Proceedings of $12^{\text {th }}$ international conference ICEM 12, Bari, (2004) 